\title{
Barriers Effecting Successful Implementation of E-Learning in Saudi Arabian Universities
}

\author{
https://doi.org/10.3991/ijet.v12i06.7003 \\ Quadri Noorulhasan Naveed \\ International Islamic University Malaysia, Kuala Lumpur, Malaysia \\ quadri.nn@live.iium.edu.my \\ Abulhafeez Muhammed \\ King Khalid University, Kingdom of Saudi Arabia \\ hafeezy@kku.edu.sa \\ Sumaya Sanober \\ Prince Sattam Bin AbdulAziz University, Al Kharj, Kingdom of Saudi Arabia \\ s.sanober@psau.edu.sa \\ Mohamed Rafik N. Qureshi \\ King Khalid University, Kingdom of Saudi Arabia \\ mrnoor@kku.edu.sa \\ Asadullah Shah \\ International Islamic University Malaysia, Kuala Lumpur, Malaysia \\ asadullah@iium.edu.my
}

\begin{abstract}
Advancement of digital technology is influencing the leaping development of various activities in our daily life. E-Learning system has also gained a competitive edge over the prevailing traditional methodology. The prevailing pedagogy is being replaced by the E-Learning teaching system. ELearning teaching-learning methodology provides more flexibility and allows freedom from time, place, physical presence, hectic, and stressful teachinglearning etc., thus plays a vital role in education system. However, there are many barriers in E-Learning methodology for successful teaching-learning. Study on such barriers will help to overcome the difficulties to the success of ELearning. Present research paper attempts to study the various barriers that are affecting the successful implementation of E-Learning in Saudi Arabian Universities. This study reviews various barriers from literatures and identified most important E-Learning barriers which are described and grouped in four dimensions such as Student, Instructor, Infrastructure and Technology, and Institutional Management. Sixteen barriers falling under these relevant dimensions were validated their importance quantitatively through university Students, Instructors, and E-Learning staffs of some well know universities in Saudi Arabia. A survey instrument was developed and tested on a sample of 257 respondents of Saudi Arabian Universities. It was found that Infrastructure and Technology Dimension is the most significant as perceived by respondents. Re-
\end{abstract}


sults of the study also reveal that, all barrier factors are highly reliable, therefore should be taken care for successful implementation of E-Learning systems.

Keywords-E-learning, E-learning Barriers, Saudi Arabia. Questionnaire survey, Statistical Analysis, Cronbach's alpha

\section{$1 \quad$ Introduction}

Revolution of digital technology has a positive influence over the various day-today activities of human lives. Apart from other sectors, education sector promoting teaching-learning activities is also influenced in a big way. The traditional pedagogy has undergone a revolutionary change because of the leaping changes of Information and Communication Technologies (ICTs) in the last decades [1]. The ongoing changes in digital technology offers tremendous prospects for various sectors like industrial sectors, medical sectors, banking sectors, education sectors etc. for improving the living standards. Industrial sectors are keen on upgrading its human skills through various online training programs. Online training courses help them to acquire much needed skills for accomplishing higher productivity in their respective fields. In the last decade of 20th century, universities are much more influenced due to digital technology and beefing up for 'E-learning' [2]. Positive developments in Internet and telecommunication technologies has removed the barriers of time, distance, place, etc. and provides much leisure in teaching-learning activities. There are dramatic changes in the learning environment [3]. Nowadays, universities around the world attempt to take the maximum benefit out from the technological revolutions and provide a better teaching-learning environment for various stakeholders. Students, teachers, and administrations are mostly benefited in the digitally connected world [2].

Initially E-learning was implemented successfully in the developed countries. Subsequently their developed operational models became benchmark for others to follow. Many universities across the globe have adopted their operational models to remain operative in the teaching-learning activities. However the success of their operation model was influenced by the specific critical success factors (CSFs) and barriers related to that part of the globe. There is tremendous influence of culture, social life, and living standards on the success of E-Learning. The degree of influence of such factors may vary form one part to another part of the globe. Hence, it is obvious that the operational model of successful implementation of E-Learning in developed countries may needs to be investigated and tested to apply the strategies in different countries with culture and social changes. The past studies has also confirmed that CSFs and barriers have different degrees of influence over E-Learning system[4] [5].

The ministry of education of the Kingdom of Saudi Arabia takes necessary cares for university-level education and provides educational reforms from time to time. The ministry of education has recognized the needs of E-Learning in public universities. The E-Learning teaching methodology has been opted rigorously in the education of boys and girls. However, the need of E-Learning system is much more felt because of the gender based educational system. E-Learning system in KSA provides equal 
opportunity to all aspirants seeking education irrespective of their gender. There is a massive demand from students, who are willing to engage in part-time jobs and really wish to continue their studies for better opportunities in future [6]. It has been well established that E-learning requires massive investments in hardware and software infrastructure to become productive, and successful in E-Learning system. However, it has been seen that the success gained in the E-Learning system is not directly proportional to the investment made. Similarly, it has been seen that the effective implementation of E-learning through many Saudi Arabian Universities do not seem proportional to the huge government investments in technology for education [2].

Present research investigates the potential barriers towards more effective adoption and implementation of E-learning in Saudi Arabia. To achieve this objective, research has been conducted in two phases. In the first-step, studies and literatures on Elearning have been rigorously reviewed and analyzed by highlighting the barriers that are restricting the full advantages of E-Learning. In the second-step, a questionnaire based survey has been conducted among the stake holders of the E-Learning i.e. students, Instructors, and Staff members in Saudi Arabian Universities. The main objectives of the study are to know the importance of each barrier related to various dimensions (main-criteria) like Student, Instructors, Infrastructure and Technology, and Institutional Management in the Saudi Arabian Universities.

The paper is organized in the following manner: Section 2 discusses related literatures and introduces the term E-learning and throws some lights on its advantages. Sections 3 presents description of the research methods and procedures used in generating the indicators of each E-Learning barriers. In Section 4, the findings based on the results obtained from the present study is discussed, the main barriers related to Elearning implementation derived from literature are documented, and importance of each barrier is obtained by analyzing the questionnaire-survey. Finally, in Section 5 the paper concludes with significant findings, discussions, and scopes for future research.

\section{$2 \quad$ Literature Review}

\subsection{Definition of E-Learning}

We are using different definitions and terms for learning with the help of technology. Use of technology enhances the quality level of learning and teaching among the stakeholders. For this ongoing research purpose, E-Learning term is defined as, "innovative approach to education delivery via electronic forms of information that enhance the students' skills, knowledge, or other learning performance" [7]. Other scholars define the term E-learning as the usage of new and modern Information and Communications Technology (ICT) with the help of networks of computers to provide learning materials, teaching, and information to stakeholder [8]. Here stakeholders of the E-learning systems are Students, Instructors, Technical and Administrative staffs, and higher authorities of the university [9]. Some other studies also used and 
related other terminologies for E-Learning such as Online Learning, Online Education, E-Education, and Distance and open learning.

\subsection{Benefits of E-Learning}

[1] summarized some important E-Learning benefits from the literature.

1. Effective interaction among Students and Instructors: E-Learning offers alternative openings for interaction among stockholders even after normal office work hours.

2. Easy Accessibility of Information: students can easily access the required learning materials from anywhere, whenever they are free. E-Learning can also help in fulfilling the needs of some learners' special needs.

3. Reducing the cost of Teaching and Learning: E-Learning can exclude traveling expenses, and save time and effort. Additionally, Learners can also get reduction in fee structures for E-Learning courses.

4. Enhancing Teaching Quality: E-learning can help Instructors to integrate pedagogical theories and multimedia enabled system and make lessons more interactive and interesting for Students.

5. Learner-Centered and Self-Paced Learning Environment: Sometimes the difference in age group and background subject knowledge effect students learning ability, in this case, face to face learning approach with a teacher does not work properly. ELearning is more suitable in such environment.

6. Ease of tracking attendance and activities of Students: E-Learning Learning Management Systems (LMS) provides rich log files of the users that track students' activities in the system.

\subsection{Current Status of E-Learning in Saudi Arabian Universities}

The Kingdom of Saudi Arabia, is the biggest Arab state by land area in the Western Asia. It covers most of the Arabian Peninsula. Saudi Ministry of Education monitors institutes of higher education and universities which offer different courses ranging from Diploma, Bachelors, Masters, and $\mathrm{PhD}$ degree in humanities and scientific specialization. The General Organization for Technical Education \& Vocational Training (GOTEVOT), which is a Saudi government authority for vocational and technical education established E-Learning center for training staff and students in 2002. This was the starting point of online education in The Kingdom of Saudi Arabia. The Saudi Ministry of Education also recognized the importance and need of Elearning in public universities where exists the shortage of female teaching staff members in the gender segregated educational institutions. There is also huge demands from those students who are mostly working as part-time and want to study in their leisure time for getting better employment in future[10] [6].

This was the major reason that The National Centre of E-learning and Distance Learning (NCeDL) was established by the Saudi Ministry of Higher Education to guide the essential changes and establish the system to provide and prepare ELearning teaching materials [11]. This initiative had excellent results and many uni- 
versities were agreed to integrate the E-Learning system with the traditional educational system [12] [11].

At the beginning, NCeDL worked and coordinated with some established Elearning service providing companies. Jusur was developed with the help of wellknown Malaysian METEOR company, Maknaz learning object repository will be developed in tandem with HarvestRoad Hive, an Australian based-company, and Makanz content will be developed initially by TATA Interactive Systems, a leading Indian E-Learning company. This is how almost all the Saudi Universities have remarkably increased their focus on E-Learning. The universities like Taiba University, King Saud University (KSU), King Abdul Aziz University (KAU), King Khalid University (KKU), Qassim University, Madinah Islamic University, and Al-Baha University have formal agreements with the NCeDL to establish and run E-Learning programs [13].

\subsection{Barriers related to successful implementation of E-learning}

Incorporating E-Learning into traditional teaching is somewhat difficult task which may come across different types of complications and difficulties, these problems are called E-Learning Barriers or Obstacles towards integrating E-Learning with traditional teaching. After extensive review on the literature related to Barriers towards ELearning, it is found that many researchers classified E-Learning Barriers or Obstacles into four different dimensions or themes, namely Barriers related to Students, Barriers related to Instructor, Barriers related to Infrastructure and Technology, Barriers related to Institutional Management.

\section{$3 \quad$ Research methodology}

To know the most important barriers which may obstacle in successful implementation of E-Learning at Saudi Arabian universities, a mixed method was used. At the beginning of the study, recent literatures were reviewed in detail and analyzed to determine and conclude the items relevant to barriers of E-Learning with different dimension through content analysis qualitative techniques. Different studies were selected from ScienceDirect, IEEE, Emerald Publishers, Taylor and Francis, Springer and Google scholar data-bases. The methodology for this research were analyzed and synthesized data using one of the popular qualitative techniques with content analysis.

Later, to validate the extracted factors, a survey approach was used involving 247 Students, Instructor and staff members of different universities in Saudi Arabia. SPSS v22 Windows software program is used to analyze the responses of the survey. At the beginning the initial design draft of the survey instrument was reviewed by four experience staff members with more than 10 years of teaching and managing E-Learning courses to establish the content validity of the instrument. The survey comprises of two main parts. First part contains demographic questions on association of ELearning, Gender, College of Teaching or Studying, E-Learning experience (number of years' as an E-Learning user), Designation, University name, Purpose and Fre- 
quency of using E-Learning teaching, and University. Second part is divided into four dimensions, namely: Student, Instructor, Infrastructure and Technology, and Institutional Management with 16 barriers factors. The survey consists of five-point scale items ( 1 for Not Important, 2 for Slightly Important, 3 for Moderately Important, 4 for Important, and 5 for Very Important).

\subsection{Content validity analysis}

In the Beginning the preliminary survey instrument was discussed and reviewed by four experienced E-Learning expert with more than 10 years of E-Learning teaching and administration experience to check the importance of each Dimensions as well as its Barrier Factors and the degree of the instrument clarity, contents of the survey and difficulty of the presented items.

The experienced expert were agreed that the items are applicable based on the current research objectives and the items are representative to check the importance of the Barriers related to successful and effective implementation of E-learning.

Table 1. Experts rating for each Dimensions' Content Validity

\begin{tabular}{lccccc}
\hline \multirow{2}{*}{\multicolumn{1}{c}{ Items }} & \multicolumn{4}{c}{ Experts } & \multirow{2}{*}{ CVI } \\
\cline { 2 - 5 } & $\mathbf{1}$ & $\mathbf{2}$ & $\mathbf{3}$ & $\mathbf{4}$ & 1.00 \\
\hline Students' Dimension & $\sqrt{ }$ & $\sqrt{ }$ & $\sqrt{ }$ & $\sqrt{ }$ & 1.00 \\
\hline Instructors' Dimension & $\sqrt{ }$ & $\sqrt{ }$ & $\sqrt{ }$ & $\sqrt{ }$ & 1.00 \\
\hline Infrastructure and Technology Dimension & $\sqrt{ }$ & $\sqrt{ }$ & $\sqrt{ }$ & $\sqrt{ }$ \\
\hline Institutional Management Dimension & $\sqrt{ }$ & $\sqrt{ }$ & $\sqrt{ }$ & $\sqrt{ }$ & 1.00 \\
\hline
\end{tabular}

\subsection{Reliability analysis}

Reliability is normally defined by measuring the internal uniformity of components with the uses of Cronbach's alpha $(\alpha)$, which is commonly used to measure the inner consistency. It presents integrity strength of a set of items in a group or dimension. The factor is carefully weighed as a degree of scale reliability. A high value of Cronbach's alpha $(\alpha)$ does not indicate the degree as unidimensional. To evaluate inner consistency, the value of alpha will provide evidence of the scale as unidimensional and additional examinations or research may be conducted on the point. Another method, known as exploratory factor analysis, is used to check the dimensionality. Basically, the Cronbach's alpha $(\alpha)$ is not representing a statistical value. The alpha is nothing but a coefficient of consistency or reliability. The alpha $(\alpha)$ which is presented in Eq. (1), is a function of test item number $(N)$ and average of inter-correlation.

$$
\alpha=\frac{N \cdot \bar{c}}{\bar{v}+(N-1) \cdot \bar{c}}
$$

Here, $N$ is presenting the item number, $\bar{v}$ is presenting the average variance, and $\bar{c}$ is indicating the average inter-item covariance of the test items.

It is clearly seen from Eq. (1) that, if the number of items $(N)$ is increased by some value, Cronbach's alpha $(\alpha)$ will increase. On the other hand, with the decreasing 
value of average inter-item correlation, Cronbach's alpha $(\alpha)$ will be decreased. Moreover, with the increment of the average value of inner-item correlation, the alpha value will be in increasing as well.

High reliability exists in the instrument with the value of 0.973 based on 16 items. Table 2 shows the Cronbach's Alpha reliability coefficient for each of the four Dimensions: Student $=0.905$, Instructor $=0.934$, Infrastructure and Technology Dimension $=0.918$, and Institutional Management $=0.890$.

Table 2. Reliability Analysis: Barriers of E-Learning

\begin{tabular}{lcc}
\hline \multicolumn{1}{c}{ Dimensions } & No. of Items & Cronbach's alpha \\
\hline Students' Dimension & 4 & 0.905 \\
\hline Instructors' Dimension & 5 & 0.934 \\
\hline Infrastructure and Technology Dimension & 3 & 0.918 \\
\hline Institutional Management & 4 & 0.890 \\
\hline Total & 16 & 0.973 \\
\hline Source: Calculation from Primary data using SPSS 22.0) & &
\end{tabular}

\section{$4 \quad$ Finding}

After reviewing the detailed literature, study identified 16 most important Barriers of E-Learning which were grouped in four dimensions having same theme such as 1) Student, 2) Instructor 3) Infrastructure and Technology Dimension. 4) Institutional Management. Each dimension included several factors that can be explained as follows:

\subsection{Students' Dimensions}

Among the different dimensions of E-Learning, Students' dimension is most important. In fact, in universities E-Learning is made available so that students can learn [14]. Since Students are away from the Instructors, some difficulties can come across. Table 3 shows the important barrier factors falling under the student's dimension from different resources.

Table 3. Barriers: Student's Dimension

\begin{tabular}{ll}
\hline \multicolumn{1}{c}{ Factor } & \multicolumn{1}{c}{ Resources / References } \\
\hline Lack of ICT skills & {$[15],[1],[16],[17],[18],[19],[20],[21],[18],[22],[23]$} \\
\hline Lack of E-Learning knowledge & {$[15],[1],[24],[25]$} \\
\hline Lack of English language proficiency & {$[2],[26],[27],[27]$} \\
\hline Lack of Motivation & {$[1],[14],[28],[27],[29],[30],[31]$} \\
\hline
\end{tabular}

While getting the quantitative results through survey, it was also found in Table 4 that most of the respondents agreed about the importance of barrier factors of student dimension for successful implementation of E-Learning having mean in between 3.20 
to 3.63. It can be concluded from the data in Table 4 that among all the respondents, "Lack of Motivation" is having the highest mean value (3.63). Therefore, it is considered as the most significant factor. "Lack of ICT skills" having least mean value (3.20) which is the least significant barrier factor for the successful implementation of E-Learning. The average mean for all barrier factors in Student's Dimension is 3.45.

Table 4. Barriers: Student's Dimension

\begin{tabular}{lccc}
\hline \multicolumn{1}{c}{ Factors } & Mean & N & Std. Deviation \\
\hline Lack of ICT skills & 3.20 & 257 & 1.304 \\
\hline Lack of E-Learning knowledge & 3.54 & 257 & 1.369 \\
\hline Lack of English language proficiency & 3.42 & 257 & 1.065 \\
\hline Lack of Motivation & 3.63 & 257 & 1.221 \\
\hline
\end{tabular}

(Source: Calculation from Primary data using SPSS 22.0)

\subsection{Instructors' Dimensions}

Instructor is also important entity of E-Learning System. Many researchers discussed different Barriers related to Instructor, especially on the ICT skills and ELearning training of the Instructor because lack of these skills will affect significantly on the confidence of Instructor in the use of technology and they will try to escape from using it. [2] Summed up some studies to show that If Instructors with positive attitude and required technical knowledge, they can use E-Learning system compare to others. Some of the important barriers under Instructor Dimension are discussed in the literature as shown in Table 5.

Table 5. Barriers: Instructor's Dimension

\begin{tabular}{ll}
\hline \multicolumn{1}{c}{ Factor } & \multicolumn{1}{c}{ Resources / References } \\
\hline Lack of ICT skills & {$[1],[32],[16],[24],[17],[26],[28],[18],[19],[21][22],[23]$} \\
\hline Lack of E-Learning knowledge & {$[1],[17],[14],[31],[25]$} \\
\hline Instructors Resistance to change & {$[33],[16],[16][24],[34],[17]$,} \\
\hline Lack of time to develop e-courses & {$[2],[33],[16],[18],[21],[29],[22],[35],[30],[23],[25]$} \\
\hline Lack of Motivation & {$[1],[17],[22],[35],[23]$} \\
\hline
\end{tabular}

While getting the quantitative results through survey, it was also found in Table 6 that most of the respondents agreed about the importance of barrier factors of instructor dimension for successful implementation of E-Learning having mean in between 3.31 to 3.70. It can be concluded from the data in Table 6 that among all the respondents, "Lack of Time to Develop E-courses" is having the highest mean value (3.70). Therefore, it is considered as the most significant factor. "Lack of ICT skills" having least mean value (3.31) which is the least significant barrier factor for the successful implementation of E-Learning. The average mean for all barrier factors in Instructor's Dimension is 3.57 . 
Table 6. Barriers: Instructor's Dimension

\begin{tabular}{lccc}
\hline \multicolumn{1}{c}{ Factors } & Mean & N & Std. Deviation \\
\hline Lack of ICT skills & 3.31 & 257 & 1.255 \\
\hline Lack of E-Learning knowledge & 3.63 & 257 & 1.367 \\
\hline Resistance to change & 3.66 & 257 & 1.215 \\
\hline Lack of Time to Develop E-courses & 3.70 & 257 & 1.287 \\
\hline Lack of Motivation & 3.55 & 257 & 1.148 \\
\hline (Source: Calculation from Primary data using SPSS 22.0) & & &
\end{tabular}

\subsection{Infrastructure and Technology Dimensions}

Technical Dimension plays major role in E-Learning and it is fundamental part in successful implementation of E-Learning. It also required huge finances which make it very expensive to proper implementation and maintenance [5]. For successful implementation of E-Learning, organizations need to ensure appropriate Hardwares, Softwares, Internet connectivity, and Technical Support system. Some of the important barriers under Infrastructure and Technology Dimensions are discussed in the literature as shown in Table 7.

Table 7. Barriers: Infrastructure and Technology Dimension

\begin{tabular}{ll}
\hline \multicolumn{1}{c}{ Factor } & \multicolumn{1}{c}{ Resources / References } \\
\hline Inappropriate Infrastructure & {$[15],[1],[32],[36],[24],[17],[26],[37],[18],[19],[21],[22],[35],[23]$,} \\
& {$[30],[25]$} \\
\hline Low internet bandwidth & {$[1],[32],[36],[17],[38],[27],[19],[20],[21],[35],[23],[30],[31]$} \\
\hline Lack of technical support, & {$[1],[2],[33],[39],[36],[24],[20],[40],[22],[41], .[35],[31]$} \\
\hline
\end{tabular}

While getting the quantitative results through survey, it was also found in Table 8 that most of the respondents agreed about the importance of barrier factors of Infrastructure and Technology dimension for successful implementation of E-Learning having mean in between 3.51 to 3.67 . It can be concluded from the data in Table 8 that among all the respondents, "Low Internet Bandwidth" is having the highest mean value (3.67). Therefore, it is considered as the most significant factor. "Inappropriate Infrastructure" having least mean value (3.51) which is the least significant barrier factor for the successful implementation of E-Learning. The average mean for all barrier factors in Infrastructure and Technology Dimension is 3.61.

Table 8. Barriers: Infrastructure and Technology Dimension

\begin{tabular}{lccc}
\hline \multicolumn{1}{c}{ Factors } & Mean & N & Std. Deviation \\
\hline Inappropriate Infrastructure & 3.51 & 257 & 1.364 \\
\hline Low Internet Bandwidth & 3.67 & 257 & 1.285 \\
\hline Lack of Technical Support & 3.65 & 257 & 1.232 \\
\hline (Source: Calculation from Primary data using SPSS 22.0) & & &
\end{tabular}




\subsection{Institutional Management Dimensions}

In the present time, universities around the world are trying to get benefits from the present technological revolution and are attempting to offer the best possible support for Students and Instructors, but many developing countries are facing different challenges in implementing successful E-Learning [2]. Some of the important barriers related to Institutional Management Dimensions are discussed in the literature are shown in Table 8.

Table 9. Barriers: Infrastructure and Technology Dimension

\begin{tabular}{ll}
\hline \multicolumn{1}{c}{ Factor } & \multicolumn{1}{c}{ Resources / References } \\
\hline Lack of Financial Support & {$[15],[32],[1],[42],[24],[34],[43],[28],[18],[27],[19],[22]$} \\
\hline Lack of Inadequate Policies & {$[15],[1],[2],[42],[32],[24],[17],[18],[31]$} \\
\hline Lack of Training on E-Learning & {$[15],[1][2],[33],[24],[36],[30]$} \\
\hline Lack of Instructional Design & {$[2],[35]$} \\
\hline
\end{tabular}

While getting the quantitative results through survey, it was also found in Table 10 that most of the respondents agreed about the importance of barrier factors of Institutional Management Dimensions for successful implementation of E-Learning having mean in between 3.39 to 3.62. It can be concluded from the data in Table 10 that among all the respondents, "Lack of Training in E-Learning" is having the highest mean value (3.62). Therefore, it is considered as the most significant factor. "Lack of Instructional Design" having least mean value (3.39) which is the least significant barrier factor for the successful implementation of E-Learning. The average mean for all barrier factors in Institutional Management Dimension is 3.50.

Table 10. Barriers: Institutional Management Dimension

\begin{tabular}{lccc}
\hline \multicolumn{1}{c}{ Factors } & Mean & N & Std. Deviation \\
\hline Lack of Financial Support & 3.55 & 257 & 1.380 \\
\hline Lack of Inadequate Policies & 3.46 & 257 & 1.224 \\
\hline Lack of Training in E-Learning & 3.62 & 257 & 1.164 \\
\hline Lack of Instructional Design & 3.39 & 257 & 1.137 \\
\hline
\end{tabular}

(Source: Calculation from Primary data using SPSS 22.0)

\section{$5 \quad$ Discussion and Conclusion}

From literature survey, it is found that, 16 barrier factors which are the most significant in effective and successful E-Learning implementation in Saudi Higher Educational Institutes. Thus, this study was conducted to identify the E-Learning variables that influence the uses and success of E-Learning. The findings from the content validity analysis and reliability analysis of the instrument indicate the high validity and reliability of the system. Thus, researchers may suggest to take care these barrier factors for successful E-Learning systems. Data collected from this study and previous researches reflect differences in Cronbach's alpha values. This may because of 
the respondent's background, curricula, culture, facilities, or the items used in the instrument. This study considers all four dimensions of E-Learning, which are Student, Instructor, Infrastructure and Technology and Institutional Management. It was found that Infrastructure and Technology Dimension having mean 3.61 is the most significant while Students' Dimension having mean 3.45 is least significant as perceived by respondents. Moreover, Lack of Time to Develop E-courses barrier Factor having mean 3.70 is most significant among all sixteen factors while Lack of ICT skills for Students is least significant with mean value as 3.20. This study reviewed the most important Barriers of E-Learning acquired from the extensive literature survey and developed a survey instrument incorporating the attained Barrier Factors for the better effectiveness of E-Learning system. It can be concluded that, Student, Instructor, Infrastructure and Technology and Institutional Management dimensions are the most important dimensions to influences the usages of E-Learning systems. Thus we recommend that institutions should provide more attention to above said barrier factors of E-Learning to ensure more successful implementation of an E-Learning system. The questionnaire used in this study focuses on the perceived effect of each factor dimension based on overall E-Learning effectiveness. It is recommended to use this instrument in various contexts for the purpose of developing, implementing, and assessing E-Learning systems properly. Another prospective could be the implementation of an E-Learning model, and investigating its learning effectiveness. Furthermore, the factors incorporating all the four dimensions can be prioritized to find more effective barriers. Assessment of barrier factors contributes significantly to effective E-Learning process. However, the influence of such barriers may vary from region to region depending upon the social, economic, and geographical conditions of a country. In this research, assessment have been established in the Kingdom of Saudi Arabia (KSA).

\section{References}

[1] A. Al-Azawei, P. Parslow, and K. Lundqvist, "Barriers and Opportunities of E-Learning Implementation in Iraq: A Case of Public Universities," Int. Rev. Res. Open Distrib. Learn., vol. 17, no. 5, 2016.

[2] M. A. Al Gamdi and A. Samarji, "Perceived Barriers towards e-Learning by Faculty Members at a Recently Established University in Saudi Arabia," Int. J. Inf. Educ. Technol., vol. 6, no. 1, p. 23, 2016. https://doi.org/10.7763/IJIET.2016.V6.652

[3] M. Aparicio, F. Bacao, and T. Oliveira, "Grit in the path to e-learning success," Comput. Human Behav., vol. 66, pp. 388-399, 2017. https://doi.org/10.1016/j.chb.2016.10.009

[4] A. Muhammad, M. F. M. D. Ghalib, F. Ahmad, Q. N. Naveed, and A. Shah, "A Study to Investigate State of Ethical Development in E-Learning," J. Adv. Comput. Sci. Appl., vol. 7, no. 4, 2016. https://doi.org/10.14569/ijacsa.2016.070436

[5] M. M. Alkharang and G. Ghinea, "E-learning in higher educational institutions in Kuwait: Experiences and challenges," E-learning, vol. 4, no. 4, 2013.

[6] H. S. Al-Khalifa, "E-Learning and ICT Integration in Colleges and Universities in Saudi Arabia.," eLearn Mag., vol. 2010, no. 3, p. 3, 2010.

[7] O. XaymoungNhoun, W. Bhuasiri, J. J. Rho, H. Zo, and M.-G. Kim, "The critical success factors of e-learning in developing countries,” Korea, vol. 305, p. 701, 2012. 
[8] H. M. Selim, "Critical success factors for e-learning acceptance: Confirmatory factor models," Comput. Educ., vol. 49, no. 2, pp. 396-413, 2007. https://doi.org/10.1016/j.compedu. 2005.09.004

[9] S. Ozkan and R. Koseler, "Multi-dimensional students' evaluation of e-learning systems in the higher education context: An empirical investigation," Comput. Educ., vol. 53, no. 4, pp. 1285-1296, 2009. https://doi.org/10.1016/j.compedu.2009.06.011

[10] A. Clementking, A. Muhammad, A. Shah, and F. Ahmad, "Technology Based Learning Analysis of CBCS Model at KKU,” Int. J. Emerg. Technol. Learn., vol. 8, no. 3, 2013.

[11] H. Al-Dosari, "Faculty members and students perceptions of E-learning in the english department: A project evaluation," J. Soc. Sci., vol. 7, no. 3, p. 291, 2011.

[12] K. Musbahtiti and A. Muhammad, "Improvement quality of LMS through application of social networking sites.," Int. J. Emerg. Technol. Learn., vol. 8, no. 3, 2013.

[13] A. M. Al-Asmari and M. S. R. Khan, "E-learning in Saudi Arabia: Past, present and future," Near Middle East. J. Res. Educ., 2014.

[14] A. Assareh and M. H. Bidokht, "Barriers to e-teaching and e-learning," Procedia Comput. Sci., vol. 3, pp. 791-795, 2011. https://doi.org/10.1016/j.procs.2010.12.129

[15] J. D. Stoffregen et al., "Barriers to open e-learning in public administrations: A comparative case study of the European countries Luxembourg, Germany, Montenegro and Ireland," Technol. Forecast. Soc. Change, vol. 111, pp. 198-208, 2016. https://doi.org/10.1016/j.techfore.2016.06.030

[16] V. Smy, M. Cahillane, and P. MacLean, "A case study of the barriers and enablers affecting teaching staff e-learning provision," 2016.

[17] T. Kenan, C. Pislaru, and A. Elzawi, "Trends and policy issues for the e-learning implementation in Libyan universities," Int. J. Trade, Econ. Financ., vol. 5, no. 1, p. 105, 2014.

[18] M. Khan, S. Hossain, M. Hasan, and C. K. Clement, "Barriers to the Introduction of ICT into Education in Developing Countries: The Example of Bangladesh.," Online Submiss., vol. 5, no. 2, pp. 61-80, 2012.

[19] M. U. Shaikh and A. Shamim, "Barriers Faced by Under Developed Countries in Promotion of Web Based e-Learning," Int. Inf. Inst. (Tokyo). Inf., vol. 15, no. 10, p. 4019, 2012.

[20] G. Ssekakubo, H. Suleman, and G. Marsden, "Issues of adoption: have e-learning management systems fulfilled their potential in developing countries?," in Proceedings of the South African Institute of Computer Scientists and Information Technologists Conference on Knowledge, Innovation and Leadership in a Diverse, Multidisciplinary Environment, 2011, pp. 231-238. https://doi.org/10.1145/2072221.2072248

[21] H. Nneka Eke, "The perspective of e-learning and libraries in Africa: challenges and opportunities," Libr. Rev., vol. 59, no. 4, pp. 274-290, 2010. https://doi.org/10.1108/0024 2531011038587

[22] S. Al-Senaidi, L. Lin, and J. Poirot, "Barriers to adopting technology for teaching and learning in Oman,” Comput. Educ., vol. 53, no. 3, pp. 575-590, 2009. https://doi.org/10.1016/j.compedu.2009.03.015

[23] S. Yu, I.-J. Chen, K.-F. Yang, T.-F. Wang, and L.-L. Yen, "A feasibility study on the adoption of e-learning for public health nurse continuing education in Taiwan," Nurse Educ. Today, vol. 27, no. 7, pp. 755-761, 2007. https://doi.org/10.1016/j.nedt.2006.10.016

[24] D. Kisanga and G. Ireson, "Barriers and strategies on adoption of e-learning in Tanzanian higher learning institutions: Lessons for adopters," Int. J. Educ. Dev. Using Inf. Commun. Technol., vol. 11, no. 2, p. 126, 2015.

[25] S. Sambrook, "E-learning in small organisations," Educ. Train., vol. 45, no. 8/9, pp. 506516, 2003. https://doi.org/10.1108/00400910310508892 
[26] M. Sayed and F. Baker, "Blended Learning Barriers: An Investigation, Exposition and Solutions,” J. Educ. Pract., vol. 5, no. 6, pp. 81-85, 2014.

[27] A. Elzawi and S. Wade, "Barriers to ICT adoption in quality of engineering research in Libya: how to bridge the digital divide?," 2012.

[28] K. Becker, C. Newton, and S. Sawang, "A learner perspective on barriers to e-learning," Aust. J. Adult Learn., vol. 53, no. 2, p. 211, 2013.

[29] L. Vrazalic, R. MacGregor, and D. Behl, "E-learning barriers in the United Arab Emirates: Preliminary results from an empirical investigation,” IBIMA Bus. Rev., 2010.

[30] M.-P. Gagnon, F. L_gar_, M. Labrecque, P. Fr_mont, M. Cauchon, and M. Desmartis, "Perceived barriers to completing an e-learning program on evidence-based medicine," J. Innov. Heal. Informatics, vol. 15, no. 2, pp. 83-91, 2007. https://doi.org/10.14236/ jhi.v15i2.646

[31] L. Y. Muilenburg and Z. L. Berge, "Student barriers to online learning: A factor analytic study," Distance Educ., vol. 26, no. 1, pp. 29-48, 2005. https://doi.org/10.1080/015879 10500081269

[32] J. K. Tarus, D. Gichoya, and A. Muumbo, "Challenges of implementing e-learning in Kenya: A case of Kenyan public universities,” Int. Rev. Res. Open Distrib. Learn., vol. 16, no. 1, 2015.

[33] S. Babić, M. Čičin-Šain, and G. Bubaš, "A Study of Factors Influencing Higher Education Teachers' Intention to Use E-learning in Hybrid Environments," in Computers in education (CE), 2016. https://doi.org/10.1109/mipro.2016.7522285

[34] H. Aminu and S. Rahaman, "Barriers thrusting e-learning to the backseat: Nigeria a case study," in Humanitarian Technology Conference-(IHTC), 2014 IEEE Canada International, 2014, pp. 1-4. https://doi.org/10.1109/ihtc.2014.7147520

[35] S. Panda and S. Mishra, "E-Learning in a Mega Open University: Faculty attitude, barriers and motivators," EMI. Educ. Media Int., vol. 44, no. 4, pp. 323-338, 2007. https://doi.org/10.1080/09523980701680854

[36] F. A. A. Idris and Y. B. Osman, "Challanges Facing the Implementation of e-Learning at University of Gezira According to View of Staff Members," in 2015 Fifth International Conference on e-Learning (econf), 2015, pp. 336-348. https://doi.org/10.1109/econf. 2015.51

[37] J. Mahmood, H. M. Dahlan, and others, "Enhancement of e-learning system by using social network features," in e-Learning, e-Management and e-Services (IC3e), 2013 IEEE Conference on, 2013, pp. 24-29.

[38] B. Bell and J. E. Federman, "E-Learning Works--Exactly How Well Depends on Its Unique Features and Barriers: CAHRS ResearchLink No. 1.," Cent. Adv. Hum. Resour. Stud. Cornell Univ., 2013.

[39] O. Oleksandra, K. Sara, and L. Martina, "E-learning platform evaluation by using CoALa: Lessons learned concerning E-learning support and evaluation," in 2016 IEEE Global Engineering Education Conference (EDUCON), 2016, pp. 1034-1039. https://doi.org/10.1109/educon.2016.7474680

[40] K. Moscinska and J. Rutkowski, "Barriers to introduction of e-learning: A case study," in 2011 IEEE Global Engineering Education Conference (EDUCON), 2011, pp. 460-465. https://doi.org/10.1109/EDUCON.2011.5773176

[41] A. Andersson, "Seven major challenges for e-learning in developing countries: Case study eBIT, Sri Lanka," Int. J. Educ. Dev. using ICT, vol. 4, no. 3, 2008.

[42] N. Gcora and L. Cilliers, "Critical success factors for eLearning adoption in the public health care sector in South Africa," in IST-Africa Week Conference, 2016, 2016, pp. 1-11. 
[43] R. J. Wardoyo and N. Mahmud, "Benefits and barriers of learning and using ICTs at open university: a case study of Indonesian domestic workers in Singapore," in Proceedings of the Sixth International Conference on Information and Communication Technologies and Development: Full Papers-Volume 1, 2013, pp. 215-226. https://doi.org/10.1145/251660 $\underline{4.2516612}$

\section{Authors}

Quadri Noorulhasan Naveed is pursuing $\mathrm{PhD}$ in Information Technology from International Islamic University Malaysia (IIUM) Kuala Lumpur, Malaysia. He has completed his graduation and Masters from Dr. BAMU, Aurangabad, India. This work is carried out as part of his area of research interest and higher studies.

AbdulHafeez Muhammad is working as a lecturer in the College of Computer Science, King Khalid University, KSA since last 10 years. He has completed PhD in IT from IIUM, Malaysia. He is a reviewer for well reputed International Journals and technical committee member/organizer of International conferences. His research area is e-Learning and Education Management through ICTs. He has published handsome publications in the same field.

Sumaya Sanober pursued Bachelors and Masters with distinction from Osmania University, Hyderabad, India. She is currently working as a lecturer in the Department of Computer Science, College of Arts and Science, Prince Sattam Bin AbdulaAziz University, KSA. She has published several research papers in reputed journals.

M.N. Qureshi has completed PhD from IIT Roorkee, India. Earlier, he has completed his graduation and PG from M.S. University of Baroda, Vadodara. He has published over 100 papers Journals and conference proceedings at national/international levels. He won the Best Ph.D. Thesis award. He has guided four students for their Ph.D. He has participated in more than 30 Seminars/Conferences at National and International levels. He is a 'Certified Assessor' for National Vocational Qualification of EMTA Awards Ltd., He is also certified Chartered Engineer of Institution of Engineers (India). He is on editorial panel and reviewer of reputed International Journals.

Asadullah Shah is currently working as Professor and HoD of IS department at the Faculty of ICT IIUM, Malaysia. He did his Ph.D. from the University of Surrey UK, in 1998. He has published 180 research articles in highly reputable international and national journal in the fields of computers, communication and IT. Also, he has published 15 books in his 30 years of academic career. Professor Shah is member of various professional bodies and boards.

Article submitted 15 April 2017. Published as resubmitted by the authors 23 May 2017. 